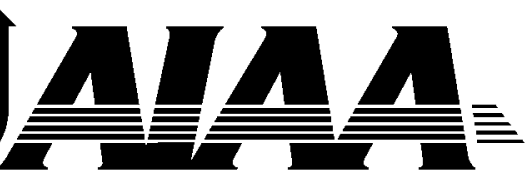

AIAA 2002-0503

Investigation of Fundamental Modeling and Thermal Performance Issues for a Metallic Thermal Protection System Design

Max L. Blosser

NASA Langley Research Center

Hampton, VA

40th Aerospace Sciences Meeting \& Exhibit 14-17 January 2002
Reno, Nevada

For permission to copy or to republish, contact the copyright owner named on the first page. For AIAA-held copyright, write to AIAA Permissions Department, 1801 Alexander Bell Drive, Suite 500, Reston, VA, 20191-4344. 
AIAA 2002-0503

\title{
INVESTIGATION OF FUNDAMENTAL MODELING AND THERMAL PERFORMANCE ISSUES FOR A METALLIC THERMAL PROTECTION SYSTEM DESIGN
}

\author{
Max L. Blosser * \\ NASA Langley Research Center, Hampton, Virginia
}

\begin{abstract}
$\underline{\text { Abstract }}$
A study was performed to develop an understanding of the key factors that govern the performance of metallic thermal protection systems for reusable launch vehicles. A current advanced metallic thermal protection system (TPS) concept was systematically analyzed to discover the most important factors governing the thermal performance of metallic TPS. A large number of relevant factors that influence the thermal analysis and thermal performance of metallic TPS were identified and quantified. Detailed finite element models were developed for predicting the thermal performance of design variations of the advanced metallic TPS concept mounted on a simple, unstiffened structure. The computational models were also used, in an automated iterative procedure, for sizing the metallic TPS to maintain the structure below a specified temperature limit. A statistical sensitivity analysis method, based on orthogonal matrix techniques used in robust design, was used to quantify and rank the relative importance of the various modeling and design factors considered in this study. Results of the study indicate that radiation, even in small gaps between panels, can reduce significantly the thermal performance of metallic TPS, so that gaps should be eliminated by design if possible. Thermal performance was also shown to be sensitive to several analytical assumptions that should be chosen carefully. One of the factors that was found to have the greatest effect on thermal performance is the heat capacity of the underlying structure. Therefore the structure and TPS should be designed concurrently.
\end{abstract}

\footnotetext{
*Aerospace Engineer, Metals and Thermal Structures Branch, Structures and Materials Competency

${ }^{1}$ Copyright (C) 2001 by the American Institute of Aeronautics and Astronautics, Inc. No copyright is asserted in the United States under Title 17, U.S. Code. The U.S. Government has a royalty-free license to exercise all rights under the copyright claimed herein for Governmental Purposes. All other rights are reserved by the copyright owner.
}

Introduction

Metallic thermal protection systems ${ }^{1,2}$ are a key technology that may help achieve the goal of reducing the cost of space access. The primary function of the thermal protection system (TPS) is to regulate the heat flow to and from the vehicle to maintain the underlying structure within acceptable temperature limits. Its thermal performance is therefore of critical concern. Commercial general-purpose computer codes can be used to calculate the thermal performance of a particular design configuration by predicting the temperature distribution in the structure and the TPS. However, there is little information available to indicate how to improve the performance of a TPS design. To understand what affects the thermal performance of metallic TPS it is important to analyze a configuration that is specific enough to provide meaningful results, but generic enough to provide a general understanding of TPS thermal performance.

Thermal analysis of metallic TPS involves modeling complex heat transfer mechanisms in a severe transient thermal environment. Pressures vary by more than five orders of magnitude and temperatures can vary from below room temperature to more than $2000^{\circ} \mathrm{F}$. Conduction, radiation and convection all play important roles in the thermal performance of metallic TPS. Material properties may vary with both temperature and pressure. Many simplifying assumptions are typically made to develop a practical thermal model. Typically, simplified, one-dimensional models ${ }^{3}$ are used to predict the thermal performance of a TPS and to size the required insulation thickness to maintain the vehicle structure within acceptable temperature limits. Guidelines are needed to determine what can be neglected and what must be included in the thermal models to obtain accurate results.

There are many design options that have the potential to improve the thermal performance of metallic TPS. An obvious way to improve the thermal performance of metallic TPS is to develop more efficient non-load-bearing insulation. Mass-efficient multilayer insulations are being characterized and optimized for use in metallic TPS. ${ }^{4}$ However, there are heat shorts in the gaps between panels and at the mechanical attachments. Better insulations may be 
ineffective if edge heat shorts are dominating the thermal performance of the TPS. Coatings may be used on various internal and external surfaces to improve thermal performance by controlling surface emittances and catalytic efficiencies. Under some conditions it may be more mass efficient to use additional thermal mass rather than additional insulation to maintain acceptable structural temperatures. Guidelines need to be developed to identify the most attractive design approaches and the range of conditions for which each is most effective.

A study was performed to develop an understanding of the key factors that govern the performance of metallic thermal protection systems for reusable launch vehicles. A current advanced metallic TPS concept, Adaptable, Robust, Metallic, Operable, Reusable $(\mathrm{ARMOR})^{5}$ TPS, was systematically analyzed to discover the most important factors governing the thermal performance of metallic TPS. A large number of relevant factors that influence the thermal analysis and thermal performance of metallic TPS were identified and quantified. Detailed finite element computational models were developed for predicting the thermal performance of variations of the advanced metallic TPS concept mounted on a simple, unstiffened structure. The computational models were also used, in an automated iterative procedure, for sizing the metallic TPS to maintain the structure below a specified temperature limit. A statistical sensitivity analysis method, based on orthogonal matrix techniques used in robust design, was used to quantify and rank the relative importance of the various modeling and design factors considered in this study.

\section{TPS Concept and Loading}

\section{Metallic TPS Concept}

For the current study a specific metallic TPS concept and a specific, realistic atmospheric entry trajectory were selected as a baseline and various assumptions and parameters were systematically varied about the baseline. Figure 1 shows a sketch of an ARMOR panel. The outer surface of the panel is comprised of a foil gage, Inconel 617 metallic honeycomb sandwich panel that is exposed to ascent and reentry heating as well as aerodynamic and acoustic pressures. A thin-gage titanium box beam frame defines the edges of the panel's inner surface. The outer honeycomb sandwich panel is structurally connected to the inner box beam by a thin Inconel 718 metal bracket at each corner of the panel. The brackets are arranged tangent to a circle about the center of the panel so that they can accommodate the thermal expansion mismatch between the hot Inconel outer surface and the cooler inner titanium frame by flexing. With this arrangement each bracket has little bending stiffness to constrain radial thermal expansion differences between the hot outer surface and cooler inner surface, yet can react drag forces and pressure loads. Each bracket is beaded to prevent buckling when loaded in compression. Mechanical fasteners connect the corners of the box beam to the substructure. A compliant, bellows-type tube provides access from the outer surface to the inner mechanical fastener. Each fastener access tube is closed off at the outer surface by a snap-in cover. Bulged, compliant sides, made of thin gauge metal foil, enclose the sides of the TPS panel and block the radiative heat transfer path in the panel-topanel gaps. A thin gauge metal foil closes out the bottom of the TPS panel. A vent, covered by fine mesh, in the metal foil backing allows the TPS internal pressure to be maintained at local atmospheric pressure, but prevents water from entering the panel interior. The interior of the panel is filled with low-density fibrous insulation. On two edges of the panel, the exterior facesheet of the honeycomb panel extends to overlap the panel-to-panel gap and inhibit ingress of hot gases during reentry.

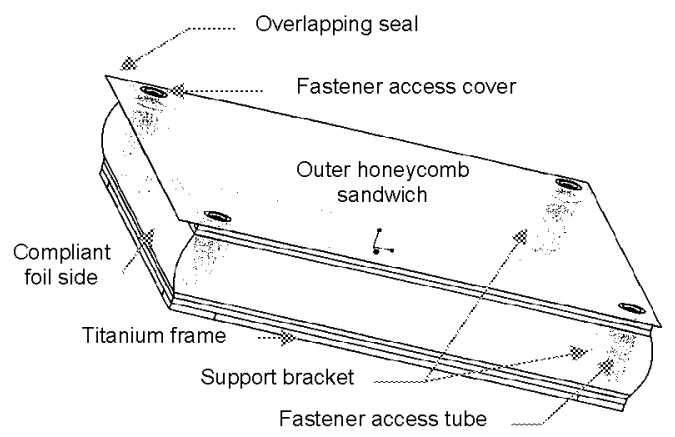

Figure 1: ARMOR TPS panel.

\section{Aerothermal Environment and Trajectory}

Thermal loads ${ }^{1}$ for a lifting body, single-stage-toorbit (SSTO) reusable launch vehicle (RLV) were used for the current study. Figure 2 shows the predicted temperature distribution on the windward surface of an RLV at peak heating. ${ }^{2}$ The solid circle indicates the location for the heating rates used in the following analyses. This location has higher heating than most of the lower surface of the vehicle.

The radiation equilibrium temperature and the local surface pressure as a function of time during atmospheric entry for the point indicated in Figure 2 are shown in Figure 3. The maximum radiation equilibrium temperature is well below the $1800-1900^{\circ} \mathrm{F}$ range where 
the superalloy honeycomb and X-33 metallic TPS ${ }^{6}$ concepts have been tested. The heating profile is characteristic of the longer, cooler trajectory flown by a large, low density, SSTO RLV. In contrast, the Shuttle Orbiter, which discards its main propellant tanks during launch, is a smaller, denser vehicle that flies a quicker, hotter entry trajectory.

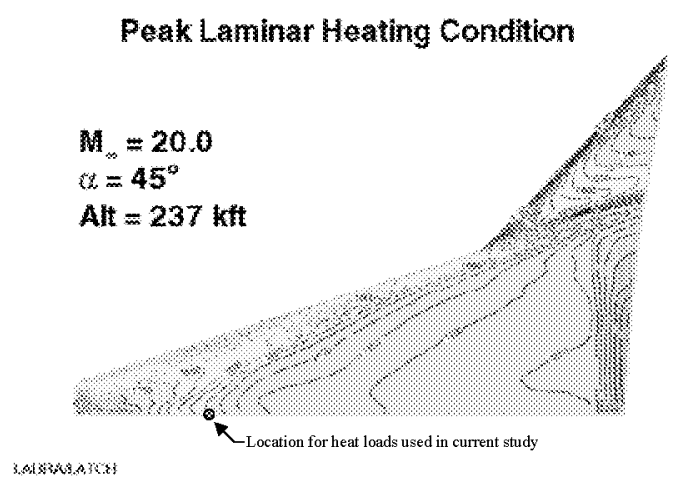

Figure 2: Temperature distribution $\left({ }^{\circ} \mathrm{F}\right)$ at peak heating on windward surface of a lifting body RLV.

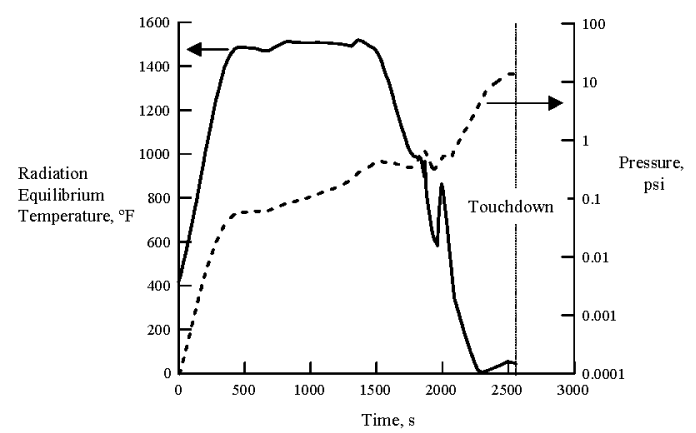

Figure 3: Typical radiation equilibrium temperature and surface pressure profile for RLV entry.

\section{Analytical Method}

\section{Finite Element Modeling}

Computational thermal models of metallic TPS panels were developed using the built-in programming language in $\mathrm{EAL}^{7-8}$ a general-purpose finite element analysis program, to generate parametric representations for convenient analysis. Variables were defined to control the panel dimensions, element meshing, and some material properties.

One of the challenges for the current study was to develop a model that represented the heat transfer through a metallic TPS panel accurately, but was efficient enough computationally to be used for TPS sizing and parametric studies. Aerodynamic heating is usually assumed constant over the surface of a single TPS panel, so a complicated model is not required for the heating boundary condition. Significant heat transfer is expected in the panel-to-panel gap, so at least a two dimensional model is required. The only compelling reason for considering a three-dimensional model would be to more accurately model temperatures around the area where the fastener attaches the TPS panel to the structure. Modeling this localized temperature distribution is only important for structural materials with such low thermal diffusivity that the maximum structural temperature occurs at this heat short location.

For the current study, a thermal model of a metallic TPS panel and a uniform thickness substructure was developed that is a hybrid between a two-dimensional and an axisymmetric model. Element thicknesses were varied so that the two-dimensional model simulated axisymmetric conduction in the interior of the panel as shown in Figure 4. This model captured the effect of the perimeter heat shorts on the temperatures in the interior of the panel and the underlying structure. For the boundary between panels, the two-dimensional symmetry condition was used. This provided a good representation of radiation and conduction heat transfer in the gap away from the panel corners. Elements representing the sides of the panel, the support bracket, and the mechanical fastener were sized to provide the correct heat shorts per unit area for a square panel. In this way a computationally efficient 2-D model was used to simulate the behavior of a 3-D TPS panel. The most significant simplification in this model is that the heat shorts due to the fastener, support bracket and fastener access tube are smeared around the perimeter of the TPS panel rather than located at discrete points, as they would be in a three-dimensional model.

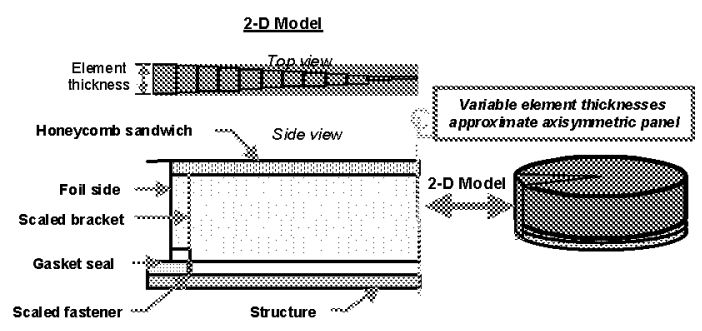

Figure 4: Variable thickness two-dimensional model of an improved metallic TPS panel.

Two-dimensional conduction elements were used to model the aluminum structure, felt gasket, fibrous insulation, honeycomb core and air in the gaps. One- 
dimensional conduction elements were used to model the honeycomb facesheets, inner titanium foil, panel sides, support bracket, and fastener. One-dimensional radiation elements were used on the lower surface of the TPS panel and the upper surface of the structure to model the radiation across the gap under the panel. Because the gap was narrow (0.135 in.) and the heat transfer was primarily across the gap, calculations were simplified by assuming that each radiation element exchanged radiation only with the element directly across the gap. One-dimensional radiation elements were also used around the perimeter of the panel-topanel gap. The primary direction of heat transfer is down the panel-to-panel gap, so radiation exchange between all the gap elements was modeled. A separate computer program was written to calculate the view factors using the crossed string method ${ }^{9}$ that accounted for the symmetry of the gap.

A similar model of an older superalloy honeycomb TPS panel design was developed to validate the present computational approach by comparing predicted results with published test data. ${ }^{10}$ Temperature histories predicted using this model matched the measured temperature histories very well. ${ }^{l}$ Therefore this finite element modeling approach was shown to be adequate for the current study.

\section{$\underline{\text { Statistical Sensitivity Analysis }}$}

One of the objectives of this study is to identify the key design drivers for the thermal performance of metallic TPS. The effects of a large number of parameters or factors needed to be quantified and compared. An efficient method was needed to assess the relative importance of many factors. The conventional approach would be to investigate one factor at a time, with the remaining factors held constant. This method is acceptable for a few variables that do not change much from their baseline values. Moreover, this "one-factor-at-a-time" method assumes that the effect of each variable is independent of variations of the other variables.

A factorial design approach can be used in which a few discrete values are chosen for each factor and all possible combinations are evaluated. However, the number of analyses required can quickly become unmanageable.

The method selected for this study borrows techniques commonly used in robust design ${ }^{11,12}$ and follows an approach that has been used for inverse heat transfer problems. ${ }^{13}$ Factors (independent variables) are varied simultaneously in a matrix of experiments (or analyses) defined by orthogonal arrays. The effects of a large number of factors, evaluated over the range of interest, can be determined efficiently using this method. The method used in this study follows closely the procedures presented in a chapter entitled "Matrix Experiments Using Orthogonal Arrays" in Reference 11 as well as similar procedures in Reference 13. The method is referred to as statistical sensitivity analysis in Reference 13, so that terminology is used here also.

The first step in statistical sensitivity analysis is to identify the factors of interest. Care must be taken to select a meaningful and reasonable range of variation for each factor. The range of variation can affect how much each factor influences the results. The selection of the factors and their ranges usually depends on engineering experience and judgment, but a good selection is essential to formulate the problem properly for meaningful results. Several levels, usually 2 to 4 , are selected to cover the range of each factor.

The next step in statistical sensitivity analysis is to determine what experiments or analyses need to be performed to determine the effects of the selected factors on the performance of the system. Orthogonal arrays are used to define the number of analyses to be performed and the combination of factor levels for each analysis. A limited number of standard orthogonal arrays $^{12}$ are available to accommodate specific numbers of factors with various levels per factor. In the orthogonal array there is a column for each factor, and each row is a particular combination of levels for each factor. The columns of the array are mutually orthogonal; that is, for any pair of columns, all combinations of factor levels occur, and they occur an equal number of times. ${ }^{11}$ The smallest standard orthogonal array is chosen to accommodate the number of factors and factor levels. Any extra columns in the orthogonal array can either be ignored or in some cases used to estimate the effects of interactions between factors.

An experiment, or in this case an analysis, is performed for every row in the orthogonal matrix with the combination of factor levels defined in that row. Interpretation of the results is straightforward. The result or results for each analysis are tabulated and the overall means for all analyses are calculated. The means for each level of every factor are also calculated. Each column of the orthogonal matrix contains an equal number of experiments at each level of the factor associated with that column. The results associated with each level of that factor are averaged to obtain the associated means. The effect of a factor level is defined as the deviation it causes from the overall mean. Therefore, the effect of each factor level can be obtained by subtracting the overall mean from the mean associated with the particular level of that factor. This 
process of estimating the factor effects is sometimes called analysis of means (ANOM).

Using ANOM the effect of each factor, called the main effects, can be determined independently. However, using this procedure it is not possible to distinguish any factor interactions from the main effects. This means that a simple additive or superposition model is assumed for the response $\eta$ :

$\eta=$ overall mean $+\sum_{\text {factors }}$ (factor effect) + error

where error is the error of the additive approximation. Thus the response for any combination of factor levels can be estimated using Equation 1. In a typical design of experiments analysis this error term would also include a contribution associated with the error in repeatability of measuring the response, $\eta$, for a given experiment. However, for the current application the response is obtained from a finite element analysis so error associated with measurement repeatability does not exist.

The results of ANOM can provide considerable insight into the effect of the various factors; however, an analysis of variance (ANOVA) can give a more accurate indication of the relative importance of the factors and provides a means of ranking the factors in order of importance. ANOVA can be used to determine the contribution of each factor to total variation from the overall mean value. The sum of squares of the differences from the mean for all the levels of a particular factor ( $\mathbf{S}$ in Tables 4, 8 and 9) provides a measure of how much that factor affects the result over the specified range. The pereentage that this sum of squares value contributes to the total for all factors $(\%$ Total SS in Tables 4, 8 and 9) gives a measure of the relative importance of that particular factor.

As part of the ANOVA, the error associated with the additive assumption expressed by Equation 1 can be estimated. Two different techniques are used in the current study for this error estimation. The method used for the error estimate depends on the number of factors and factor levels and the orthogonal matrix used in the statistical sensitivity analysis.

The sum of squares due to error ${ }^{11}$ can be calculated using the following relationship:

Sum of squares due to error $=$ (grand total sum of squares) -(sum of squares due to mean) -(sum of squares due to factors)

where the grand total sum of squares is the sum of the squares of all values for a particular result, the sum of squares due to the mean is the overall mean squared times the number of analyses (or number of rows in the orthogonal matrix), and the sum of squares due to factors is the sum of squares of all the factor effects. There are degrees of freedom associated with each of the quantities in Equation 2. The degrees of freedom for the grand total sum of squares are the number of rows in the orthogonal matrix. There is one degree of freedom associated with the mean. Each factor has one less degree of freedom than the number of levels for that factor (dof in Tables 4, 8 and 9). Therefore the degrees of freedom for the error can be calculated as follows:

(degrees of freedom for error $)=$

(number of rows in orthogonal matrix - 1)

- (sum of degrees of freedom for all factors)

The degrees of freedom for the error must be greater than zero for Equation 2 to be useful.

If there are zero degrees of freedom available for calculating error, a different method must be used to estimate the additive error. An approximate estimate of the sum of the squares due to error can be obtained by pooling the sum of squares corresponding to the factors having the lowest mean square. A rule of thumb $b^{11}$ is to use the sum of squares corresponding to the bottom half of the factors (as defined by lower mean square) and the degrees of freedom corresponding to those factors. Pooled error estimates are used for the results shown in this paper.

Once the sum of square due to error and the degrees of freedom for error have been calculated, the error variance can be estimated as follows:

Error variance $=($ sum of squares due to error $) /$ (degrees of freedom for error)

The variance ratio, $\mathrm{F}$, is a measure of how important the effects of a factor are compared to the error.

$\mathrm{F}=($ mean square due to a factor $) /($ error variance $)$

The mean square due to a factor (Mean SS in Tables 4, 8 and 9) is the sum of squares of the differences from the mean for a factor $(\boldsymbol{S S})$ divided by the degrees of freedom associated with that factor (dof).

Sizing TPS for Thermal Loads

When assessing the thermal performance of a TPS, two critical parameters emerge: the mass and the thickness of the TPS required to maintain the temperature of the underlying structure within acceptable limits. Mass is important because the TPS 
covers almost the entire external surface of a large, mass critical RLV. The importance of TPS thickness is more difficult to determine numerically, but it affects the overall packaging efficiency of the vehicle. A thinner TPS can mean a smaller, more efficient vehicle. There is a trade-off between TPS thickness and mass that will vary for different TPS concepts, vehicles and location on the vehicle. Therefore, the effect of parameters on both the mass and thickness of the improved metallic TPS is important.

To calculate the mass and thickness a method for sizing the TPS insulation thickness required to limit the substructure to a specified temperature was necessary. This task was greatly simplified by assuming that radiation in the panel-to-panel gap was eliminated by the bulged, compliant sides of the ARMOR TPS design. Eliminating gap radiation avoided the need to recalculate view factors for different insulation thicknesses.

The finite element thermal model of the ARMOR TPS was modified to size the TPS insulation thickness. The model was modularized so that only parts of the model that varied with panel dimensions were updated during the sizing process. An initial value was chosen for the insulation thickness, the initial temperature $\left(T_{\text {init }}\right)$ and a temperature limit $\left(T_{\text {lim }}\right)$ was specified for the structural temperature. After the initial thermal analysis, the recorded temperature history for every structural node was searched to find the maximum structural temperature $\left(T_{m a x}\right)$, the time the maximum temperature occurred and the node at which it occurred. The maximum structural temperature was compared to the specified limit temperature using the following convergence criteria:

$$
0.001>\left|\frac{T_{\max }-T_{\mathrm{lim}}}{T_{\mathrm{lim}}-T_{\text {init }}}\right|
$$

If the maximum structural temperature did not meet the convergence criteria the insulation was resized using the following simple equation:

$$
t_{i+1}=t_{i}\left(1+\frac{T_{\max }-T_{\lim }}{T_{\lim }-T_{i n i t}}\right)
$$

where $t$ is the insulation thickness, and $i$ refers to the iteration number. Once a new insulation thickness was calculated, the nodes and elements of the finite element model were regenerated for the new geometry and another thermal analysis was performed. This simple algorithm usually converged within 3 to 5 iterations, depending on how close the initial thickness estimate was to the final thickness.

This simple sizing algorithm works well because it is based on the physics of the problem. The difference between the limit temperature and the initial temperature is roughly proportional to the amount of heat that can be allowed through the TPS and absorbed by the structure. The amount of heat allowed through the insulation is inversely proportional to the insulation thickness.

If the maximum structural temperature was found to occur on the final time step of the analysis, the length of time for the transient analysis was increased. The sizing analysis was repeated until the maximum structural temperature was found to occur before the final time step of the analysis.

The location of the maximum structural temperature provides an important clue to the interaction between the TPS and the structure. Heat shorts due to metal conduction or radiation at the perimeter of the TPS panel allow heat to reach the structure well before the primary heat pulse diffusing through the insulation in the panel interior. If the structural material has a high thermal diffusivity, the heat from the heat shorts at the panel perimeter is rapidly spread though the entire structure. However, if the structural material has a low thermal diffusivity, the temperature in the structure under the panel perimeter may rise well above the temperature in the rest of the structure. If the structural temperature at the panel perimeter exceeds maximum structural temperature under the center of the TPS panel resulting from the heat diffusing through the insulation, the heat shorts will size the TPS panel. If the heat shorts size the TPS panel, the structure away from the TPS panel perimeter will not reach its limiting temperature and the structure will not use its full heat capacity, resulting in a thicker, heavier TPS. Maximum structural temperatures under the perimeter of the TPS panel indicated that heat shorts might have influenced the sizing. Maximum structural temperatures occurring under the center of the panel indicated the sizing was dominated by diffusion of heat through the insulation package, and there was little influence of the perimeter heat shorts.

This sizing algorithm (7) worked very well and was used to determine the insulation thickness in the statistical sensitivity analyses. Once the insulation thickness was determined, the associated TPS mass was calculated in a spreadsheet using the mass properties from Reference 1.

\section{$\underline{\text { Results }}$}

Results of the study provided a number of insights into the thermal modeling requirements for metallic 
TPS. The importance of radiation in the gaps between panels was quantified. The importance of a number of thermal modeling assumptions was investigated. The sensitivity of a number of design factors on the thermal performance of metallic TPS was calculated. These results were used to develop guidelines for future designs and thermal analyses of metallic TPS

Results from this study identify factors that have the most potential to improve metallic TPS performance. The thermal properties of the underlying vehicle structure were found to have a major impact on the thickness and mass of metallic TPS required to protect the structure, leading to the conclusion that the structure and TPS should be designed concurrently. Improved insulation properties were also shown to reduce the required thickness and mass of TPS. These results provide a basis for guiding the direction of future research in metallic TPS.

\section{$\underline{\text { Radiation in gaps between panels }}$}

One of the key thermal performance issues that was identified and quantified was the radiation in the gaps between panels. For a specific size ARMOR TPS panel (18 inch by 18 inch by 3.57-inch-thick), the substructure temperature was calculated for a range of gap widths and emittances. Figure 5 shows the ratio of structural temperature increase with and without the gap between panels. This ratio is nearly proportional to the amount of heat allowed through the TPS. From the results shown in Figure 5, two main conclusions are apparent: 1) small gaps can produce large increases in the heat reaching the structure, and 2) reducing the emittance of the gap is not an effective solution for limiting gap radiation. Therefore, the best solution is to design TPS concepts that eliminate the panel-to-panel gap.

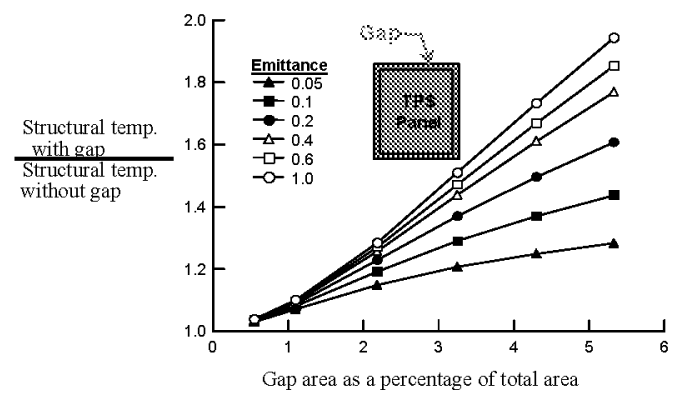

Figure 5: Effects of gap radiation as a function of gap area.

\section{Effect of Several Modeling Issues on TPS Sizing}

A number of boundary conditions and initial conditions must be defined to size the insulation required in a TPS panel. Often these conditions may not be well known and the analyst must make some assumptions to proceed with the analysis. The sensitivity of the TPS sizing to these assumptions is not usually understood. If the TPS mass or thickness is sensitive to one of these assumptions it may be more productive to spend effort better understanding and defining the assumption rather than refining the TPS design.

A statistical sensitivity analysis was performed to investigate four modeling issues: 1) the method of representing the aerodynamic heating in the finite element mode1, 2) the initial temperature of the TPS panel and structure before atmospheric entry, 3) the ambient conditions after landing, and 4) heat loss from the inner surface of the structure. Three levels were chosen for each factor associated with these modeling issues. Nine TPS sizing analyses, defined by a standard $\mathrm{L}_{9}$ orthogonal array, were run. The factors and selected levels are summarized in Table 1.

Table 1 Modeling issues for TPS sizing.

\begin{tabular}{|c|c|c|c|c|}
\hline & $\begin{array}{l}\text { Modeling } \\
\text { Factors }\end{array}$ & Level 1 & Level 2 & Level 3 \\
\hline I & $\begin{array}{c}\text { Method of } \\
\text { applying } \\
\text { aerodynamic } \\
\text { heating } \\
\end{array}$ & Convection & $\begin{array}{l}\text { Radiation } \\
\text { equilibrium } \\
\text { heating rate }\end{array}$ & $\begin{array}{l}\text { Radiation } \\
\text { equilibrium } \\
\text { temperatures }\end{array}$ \\
\hline II & $\begin{array}{c}\text { Initial } \\
\text { Temperatures } \\
\end{array}$ & $0^{\circ} \mathrm{F}$ & $60^{\circ} \mathrm{F}$ & $120^{\circ} \mathrm{F}$ \\
\hline \multirow{3}{*}{ III } & \multirow{3}{*}{$\begin{array}{l}\text { Ambient } \\
\text { Conditions } \\
\text { After } \\
\text { Landing }\end{array}$} & Cold, windy day & Average day & Hot day \\
\hline & & $\begin{array}{c}\left(0^{\circ} \mathrm{F}, 30 \mathrm{mph}\right. \\
\text { wind })\end{array}$ & $\begin{array}{c}\left(60^{\circ} \mathrm{F}, 10 \mathrm{mph}\right. \\
\text { wind })\end{array}$ & $\begin{array}{c}\left(120^{\circ} \mathrm{F}, \text { no }\right. \\
\text { wind })\end{array}$ \\
\hline & & $\begin{array}{c}\mathrm{h}=6.9 \mathrm{e}-6 \\
{\left[\mathrm{Btu} /\left(\mathrm{in}^{2} \mathrm{~s}^{\circ} \mathrm{F}\right)\right]}\end{array}$ & $\begin{array}{c}\mathrm{h}=2.5 \mathrm{e}-6 \\
{\left[\mathrm{Btu} /\left(\mathrm{in}^{2} \mathrm{~s}^{\circ} \mathrm{F}\right)\right]}\end{array}$ & $\begin{array}{c}\mathrm{h}=2.5 \mathrm{e}-7 \\
{\left[\mathrm{Btu} /\left(\mathrm{in}^{2} \mathrm{~s}^{\mathrm{o}} \mathrm{F}\right)\right]}\end{array}$ \\
\hline IV & $\begin{array}{l}\text { Structural } \\
\text { Heat Loss }\end{array}$ & None & $\begin{array}{c}\text { Radiation to } \\
\text { the initial } \\
\text { temperature, } \\
\varepsilon=0.5\end{array}$ & $\begin{array}{l}\text { Radiation to } \\
\text { the initial } \\
\text { temperature, } \\
\varepsilon=1.0\end{array}$ \\
\hline
\end{tabular}

There are a number of different methods for applying aerodynamic heating to a thermal finite element model. Radiation equilibrium conditions were assumed at the vehicle surface (the outer surface of the TPS) for almost all aerodynamic heating calculations. The heating rates are calculated for a specified surface emittance and in some cases a catalytic efficiency. The heating predictions can be given in the form of radiation equilibrium temperatures, radiation equilibrium heating rates or convective heating terms, as discussed in Reference 1. An additional method of applying aerodynamic heating is to use heating rates 
predicted for several constant wall temperatures and to interpolate between those values to obtain the heating rate for the calculated surface temperature during the thermal analysis. This method was not considered in the current study because the corresponding fixed wall temperature heating rates were not available.

The three methods of applying aerodynamic heating to the finite element model chosen for this study are: (1) applying the radiation equilibrium temperature as a transient temperature boundary condition to the outer surface of the TPS panel, (2) applying the radiation equilibrium heating rate as a transient heat flux boundary condition to the outer surface of the TPS panel, and (3) using a transient convective boundary condition with the heat transfer coefficients and recovery temperatures. All three methods use heating profiles calculated for a surface emittance of 0.86 . Applying the radiation equilibrium temperature is the least accurate and flexible of the three approaches. The actual surface temperature will be lower than the radiation equilibrium temperature, because some of the heat diffuses into the TPS panel. Therefore this approach tends to be conservative, forcing more heat into the TPS panel. Specifying the surface temperature takes surface radiation out of the problem and precludes modeling the effect of changing surface emittance.

Applying the radiation equilibrium heating rate is slightly non-conservative because it allows the surface temperature to drop below the radiation equilibrium heating temperature but does not increase the heating rate because of that lowered temperature. Changing the surface emittance in the thermal model will produce changes in the surface temperature, but the surface heating will not change accordingly

Applying the convective heating boundary condition is the most accurate and flexible of the three methods. This method not only allows the surface temperature to drop below the radiation equilibrium temperature, it also increases the heating rate to the surface for the reduced surface temperature. If the surface emittance in the thermal model is changed, the surface heating is adjusted for the resulting change in surface temperature. This method provides the best estimate for the effect of varying surface emittance on TPS thermal performance. Of course, a more accurate approach would be to recalculate the aerodynamic heating for each surface emittance of interest.

An initial temperature distribution must be specified for the finite element model before the analysis can be started. The actual temperature in a TPS panel mounted on a vehicle will depend on the vehicle configuration and its history prior to atmospheric entry. The temperature used in TPS sizing calculations also depends on the vehicle design criteria and philosophy.
The initial temperature used for TPS design may be determined by a mission abort scenario or perhaps by some nominal mission. The vehicle designer may choose the design initial temperature without understanding its impact on the resulting TPS weights and thicknesses and the impact on vehicle performance. Initial temperatures of $0^{\circ} \mathrm{F}, 60^{\circ} \mathrm{F}$ and $120^{\circ} \mathrm{F}$ were chosen for this study. These values bracket the $50^{\circ} \mathrm{F}$ to $60^{\circ} \mathrm{F}$ initial temperatures used in recent RLV studies.

In some cases the structural temperature of an RLV may not reach its maximum value until well after landing. The ambient conditions will affect the rate of heat loss from the vehicle and thus may affect the amount of TPS required. Three ambient conditions (Table 1) were chosen for the current study: 1) $0^{\circ} \mathrm{F}$ temperature with a $30 \mathrm{mph}$ wind, 2) $60^{\circ} \mathrm{F}$ temperature with a $10 \mathrm{mph}$ wind, and 3 ) $120^{\circ} \mathrm{F}$ temperature with no wind. The conditions are intended to bracket the likely landing conditions for an RLV. For forced convection, assuming a $30 \mathrm{ft}$-long flat plate (a rough approximation of the lower surface of an RLV) and transition to turbulence at a local Reynolds number of $5 \times 10^{5}$, the following equation ${ }^{14}$ was used to calculate the convection coefficient.

$\bar{N} u=\frac{h k}{L_{c}}=\left(0.037 \operatorname{Re}_{L}^{4 / 5}-871\right) \operatorname{Pr}^{1 / 3}$

where $\bar{N} u$ is the average Nusselt number, $h$ is the heat transfer coefficient, $k$ is the thermal conductivity of air, $L_{c}$ is the characteristic length $(30 \mathrm{ft}), \mathrm{Re}_{L}$ is the Reynolds number based on $L_{c}$, and $\operatorname{Pr}$ is the Prandtl number for air.

For the still air case, the following equation ${ }^{14}$ was used to calculate the natural convection coefficient:

$$
\bar{N} u=\frac{h k}{L_{c}}=0.27 \mathrm{Ra}^{1 / 4}
$$

where $\mathrm{Ra}$ is the Rayleigh number.

For TPS sizing calculations analysts commonly assume that the vehicle structure under the TPS loses no heat from its inner surface. This is a simple, usually conservative, assumption that allows the TPS to be sized without considering the complicated interior of the vehicle below the outer skin. In a real vehicle the structural skin is connected to reinforcing structure such as ribs, spars, rings or stiffeners. The skin may lose heat to the cooler vehicle interior through conduction, convection, and radiation. These heat loss modes are difficult to calculate and may be specific to a particular location on a vehicle. In a detailed thermal analysis ${ }^{15}$ 
of several wing sections and a fuselage section of the Space Shuttle Orbiter both internal radiation and internal convection were found to have a significant effect on the structural temperatures.

Three simple cases were chosen for this study to evaluate the sensitivity of TPS sizing to heat loss: 1) no heat loss, 2) radiation to the initial temperature with an emittance of 0.5 , and 3 ) radiation to the initial temperature with an emittance of 1.0. Because the actual heat loss mechanisms in a vehicle are specific to the vehicle configuration and location on the vehicle, a simple radiation heat loss mode was chosen for this study. Solid conduction to internal structural members and convection in internal cavities of the vehicle are neglected. However, the structural skin is assumed to radiate to the vehicle interior, which is assumed to remain at the initial temperature throughout the analysis. The interior of the vehicle will heat-up somewhat during entry, so this simple assumption will tend to over-predict the heat loss due to radiation possibly compensating somewhat for ignoring the other heat loss mechanisms. The radiation heat loss cases will give an indication of how sensitive TPS sizing is to the commonly used assumption of no structural heat loss.

The $\mathrm{L}_{9}$ standard orthogonal array will exactly accommodate the four factors with 3 levels each defined in Table 1. The nine computational cases required to do a statistical sensitivity analysis are defined by the orthogonal array in Table 2 .

Table $2 \mathrm{~L}_{9}$ standard orthogonal matrix

\begin{tabular}{|c|cccc|}
\hline L9 & Factors & & & \\
\hline $\begin{array}{c}\text { Analysis } \\
\text { number }\end{array}$ & I & II & III & IV \\
\hline $\mathbf{1}$ & 1 & 1 & 1 & 1 \\
$\mathbf{2}$ & 1 & 2 & 2 & 2 \\
$\mathbf{3}$ & 1 & 3 & 3 & 3 \\
$\mathbf{4}$ & 2 & 1 & 2 & 3 \\
$\mathbf{5}$ & 2 & 2 & 3 & 1 \\
$\mathbf{6}$ & 2 & 3 & 1 & 2 \\
7 & 3 & 1 & 3 & 2 \\
$\mathbf{8}$ & 3 & 2 & 1 & 3 \\
$\mathbf{9}$ & 3 & 3 & 2 & 1 \\
\hline
\end{tabular}

The results of the nine analyses defined by Table 2 are presented in Table 3 . Three columns of results are shown: TPS thickness, TPS mass, and the time when the maximum structural temperature occurred. The TPS thickness was obtained by adding the thickness of the honeycomb sandwich (0.25 in.), the thickness of the felt under the TPS panel $(0.15 \mathrm{in}$.), and the insulation thickness calculated by the TPS sizing analysis. The TPS mass per unit area is obtained from the insulation thickness and density and the mass properties for the improved metallic TPS concept listed in Reference 1. The times corresponding to the maximum structural temperature were recorded during the TPS sizing analysis.

Table 3 Results of analyses defined by orthogonal matrix.

\begin{tabular}{|c|ccc|}
\hline $\begin{array}{c}\text { Analysis } \\
\text { number }\end{array}$ & $\begin{array}{c}\text { TPS } \\
\text { thickness, in. }\end{array}$ & $\begin{array}{c}\text { TPS mass } \\
\text { per unit } \\
\text { area, } \mathbf{l b}_{\mathbf{m}} \mathbf{f t}^{\mathbf{2}}\end{array}$ & $\begin{array}{c}\text { Time for } \\
\text { maximum } \\
\text { structural } \\
\text { temperature, } \\
\mathbf{s}\end{array}$ \\
\hline $\mathbf{1}$ & 3.317 & 1.691 & 3380 \\
$\mathbf{2}$ & 2.543 & 1.474 & 2050 \\
$\mathbf{3}$ & 2.937 & 1.585 & 2180 \\
$\mathbf{4}$ & 1.772 & 1.257 & 1710 \\
$\mathbf{5}$ & 3.914 & 1.859 & 4340 \\
$\mathbf{6}$ & 2.932 & 1.583 & 2180 \\
$\mathbf{7}$ & 2.317 & 1.411 & 1980 \\
$\mathbf{8}$ & 1.983 & 1.317 & 1720 \\
$\mathbf{9}$ & 4.592 & 2.049 & 4820 \\
\hline Mean & 2.923 & 1.581 & 2707 \\
\hline
\end{tabular}

There is one surprising result in Table 3 . Vehicle touchdown occurs at about 2600s as shown in Figure 3. For six of the nine analyses, the maximum structural temperature occurs before touchdown. For these six analyses, the ambient conditions at landing can have no effect on the maximum structural temperature. The three analyses for which the maximum structural temperature occurred after landing corresponded to the assumption of no structural heat loss.

Further insight into the significance of these results can be gained by performing an ANOM and an ANOVA for both TPS thicknesses and masses. Because the TPS mass and thickness are linearly related, only the results for TPS mass are shown in Table 4. For this statistical sensitivity analysis there were no degrees of freedom available to estimate the error, so the pooled error technique was used. An asterisk indicates each of the factors used for the pooled error calculation. The calculated $\mathrm{F}$ values for factors IV and II are greater than 19 , indicating that the effects of these two factors are significantly larger than the error of the additive model.

The dominant factor is clearly structural heat loss. The difference between level 1 and level 2, corresponding to the difference between no structural heat loss and radiation to the initial temperature with an emittance of 0.5 , reduces TPS mass by $0.377 \mathrm{lb}_{\mathrm{m}} / \mathrm{ft}^{2}$, a 
change of about $24 \%$ of the mean value. TPS sizing is very sensitive to structural heat loss.

The other important factor is the initial temperature. The biggest change for this factor occurs between levels 2 and 3 , initial temperatures of $60^{\circ} \mathrm{F}$ and $120^{\circ} \mathrm{F}$. For this change the TPS mass is increased by $0.189 \mathrm{lb}_{\mathrm{m}} / \mathrm{ft}^{2}$ (12\% of mean). The difference between the initial and limit temperatures for the structure is approximately proportional to the heat storage capacity available in the structure. Specifying a high initial temperature for TPS sizing calculations may result in significant increases in TPS thickness and mass, particularly if there is a large percentage change in the difference between the initial and limit structural temperatures.

Table 4 Differences from the calculated mean TPS mass due to several modeling factors.

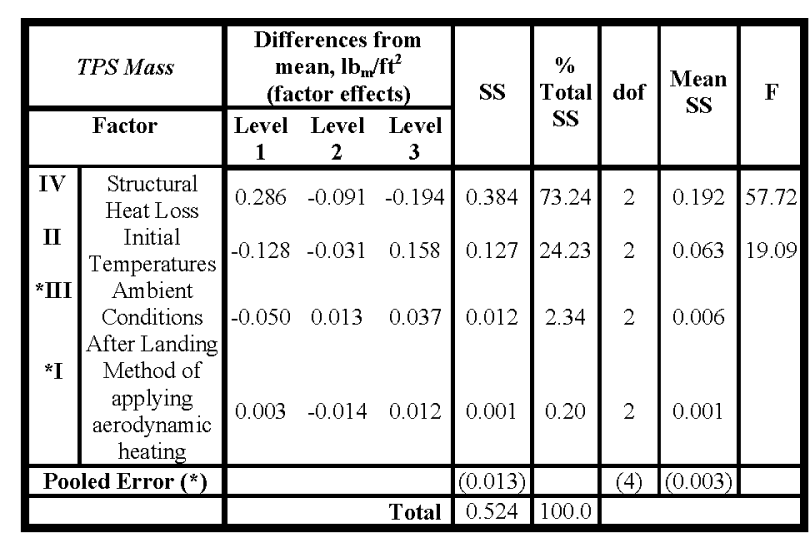

The other two factors have a much smaller effect. As discussed previously, the ambient conditions after landing have no effect on any of the cases with structural heat loss. However, there are some small changes in TPS thickness and mass due to variations in the ambient conditions. For systems with little structural heat capacity and minimal structural heat loss, this factor may be more important and merit further investigation.

The three methods of applying aerodynamic heating produced negligible variations in TPS thickness or mass. However, if the surface temperature of the TPS is expected to vary from the surface temperature assumed during the aerodynamic heating calculation (due to a change in the surface emittance or heat conduction into the TPS panel), the convective loading should be used.

\section{$\underline{\text { Statistical Sensitivity Analysis of Key Design Issues }}$}

There is a considerable amount of design flexibility for metallic TPS. Metals can be made into very thin foils, and there are many fabrication and joining techniques available so that a wide variety of massefficient configurations can be fabricated. Because internal insulation does not have to carry any mechanical loads, a wide variety of insulations can be considered. For some design issues, changes that will improve thermal performance are obvious -- lower thermal conductivity insulation and fewer heat shorts are better. However, the design issues that are most important are not always obvious. A number of design issues are identified and a statistical sensitivity analysis is used to assess their impact on sizing ARMOR TPS. The design issues are ranked according to their importance and design guidelines for metallic TPS are gleaned from the results.

\section{Identification of Key Design Issues}

The TPS mass and thickness required to maintain the temperature of the underlying structure below an acceptable limit are determined by a number of factors. The heat storage capacity of the underlying structure determines how much heat can be allowed through the TPS and the thermal performance of the TPS panel determines the thickness and mass of the TPS required to avoid overheating the structure.

The heat capacity of the structure is determined by its mass, its specific heat capacity, and by the difference between the initial temperature and the maximum allowable temperature. The thermal conductivity of the structure may also play a role in determining how much heat can be stored in the structure. A high-thermalconductivity structural material will tend to distribute heat evenly into all the available material and fully use its heat storage capacity. Thermal stresses and deformations will also tend to be reduced by uniform temperatures. A low thermal conductivity material may not distribute the heat evenly throughout the structure so that high temperatures near a heat short may size the TPS and the structural material may not use all of its available heat storage capability. For a stiffened structure, a low thermal conductivity material may not distribute heat into the stiffeners so the heat storage capacity of the structure is not fully used.

The thermal performance of a metallic TPS panel depends on a number of factors. The most obvious is the insulation. The insulation occupies the majority of the volume of the TPS panel and its sole purpose is to limit the heat reaching the underlying structure. The insulations used in previous metallic TPS designs have been high temperature, low-density fibrous insulations. These insulations are available in a variety of forms and densities. Generally, lower density insulations have higher thermal conductivities because they have fewer fibers to inhibit radiation heat transfer. Insulations 
with multiple reflective layers offer the potential for significantly reduced thermal conductivities by using thin, reflective layers to inhibit radiation, however they are currently expensive.

There are a number of necessary heat shorts in the ARMOR TPS concept. Foil sides are required to encapsulate the insulation. Support brackets are required at the corners of the panel to hold the panel together and transfer loads from the exterior surface to the internal attachments. Access tubes are required to reach the fasteners connecting the bottom of the TPS panel to the underlying structure. Of course, thermal performance of the TPS will be improved by minimizing these heat shorts, but their significance compared to other parameters in the TPS design is not known.

Radiation is an important mode of heat transfer into and through the TPS panel. The emittance of the outer surface of the TPS panel plays an important role in determining the surface temperature and aerodynamic heating. Also, heat transfer across the gap under the TPS panel consists of gas conduction and radiation. Radiation in gaps between panels can be very important, as discussed earlier, but it is assumed to be eliminated by the ARMOR TPS design. The importance of the emittance of the inner surface of the TPS panel and the outer surface of the structure is not known. If radiation across this gap is important, the surfaces could be coated to achieve the desired emittances.

\section{Statistical Sensitivity Analysis}

A statistical sensitivity analysis was performed to understand the impact of a number of design factors on metallic TPS sizing. The purpose of this analysis is to determine the relative importance of the design factors and to estimate the reductions in TPS mass and thickness that might be achievable with improved designs.

The statistical sensitivity analysis followed a similar approach to that used for modeling issues. Design factors and levels were identified. A standard orthogonal matrix was used to define the required finite element analyses. The same finite element thermal model of the ARMOR TPS panel was used to analyze each case identified, with minor modifications to accommodate some of the chosen design factors. An analysis of means (ANOM) and an analysis of variance (ANOVA) were used to evaluate the results and rank the factors in order of importance.

\section{Factor Definition}

Specific factors were identified to address the design issues previously discussed. The 13 selected design factors, each with three levels, are shown in
Table 5. These factors address structural heat capacity, insulation performance, heat shorts and emittances.

Two factors were defined to address the effect of structural heat capacity: structural mass and structural material. Typical vehicle design procedure is first to size the structure to carry the required mechanical loads, using mechanical properties reduced to account for elevated temperatures. The TPS designer is then given the task of sizing the TPS to limit that structure to an acceptable temperature. The required thickness and mass of the TPS are dependent on the configuration of the structure, the material thermal properties and the mass of the structure. For this study, only a uniform thickness structural skin was considered. The two factors were selected to separate the effects of structural mass from the effects of the thermal properties of the structural material.

Table 5 Design parameters for statistical sensitivity analysis

\begin{tabular}{|c|c|c|c|c|}
\hline \multicolumn{2}{|r|}{ Design Factors } & Level 1 & Level 2 & Level 3 \\
\hline A & $\begin{array}{c}\text { Beryllium heat sink mass, } \\
\qquad \mathrm{lb}_{\mathrm{m}^{\prime}} / \mathrm{ft}^{2}\end{array}$ & 0.0 & 0.1 & 0.2 \\
\hline $\mathrm{B}$ & Surface emittance & 1.0 & 0.8 & 0.6 \\
\hline \multirow[t]{2}{*}{ C } & Structural material & $\begin{array}{l}\text { Beryllium- } \\
\text { aluminum }\end{array}$ & Aluminum & $\begin{array}{c}\begin{array}{c}\text { Graphite/epoxy } \\
\text { composite }\end{array} \\
\end{array}$ \\
\hline & - Temperature limit, ${ }^{\circ} \mathrm{F}$ & 450 & 350 & 300 \\
\hline \multirow{4}{*}{ D } & Structural mass, $1 \mathrm{~b}_{\mathrm{m}} / \mathrm{ft}^{2}$ & 1.75 & 1.25 & 0.75 \\
\hline & - Be-Al thickness, in. & 0.1603 & 0.1145 & 0.0687 \\
\hline & - Al thickness, in. & 0.1215 & 0.0868 & 0.0521 \\
\hline & - Gr/Ep thickness, in. & 0.2132 & 0.1523 & 0.0914 \\
\hline$E$ & Insulation density, $1 \mathrm{~b}_{\mathrm{m}} / \mathrm{ft}^{3}$ & 1.5 & 3.0 & 6.0 \\
\hline $\mathrm{F}$ & $\begin{array}{l}\text { Cross-sectional area of bracket } \\
\text { and access tube, } \text { in }^{2}\end{array}$ & 0 & 0.02 & 0.04 \\
\hline $\mathrm{G}$ & $\begin{array}{l}\text { Cross-sectional area of } \\
\text { fastener, in }\end{array}$ & 0 & 0.02 & 0.04 \\
\hline $\mathrm{H}$ & Thickness of foil sides, in. & 0 & 0.002 & 0.004 \\
\hline $\mathrm{I}$ & Felt thickness, in. & 0.10 & 0.15 & 0.3 \\
\hline \multirow{3}{*}{$\mathrm{J}$} & Emittances in gap under panel & & & \\
\hline & - Inner TPS surface & 0.2 & 0.4 & 0.8 \\
\hline & - Outer surface of structure & 0.05 & 0.4 & 0.8 \\
\hline $\mathrm{K}$ & Beryllium heat sink location & Structure & $\begin{array}{l}\text { Bottom of } \\
\text { insulation }\end{array}$ & $\begin{array}{l}\text { Top of } \\
\text { insulation }\end{array}$ \\
\hline $\mathrm{L}$ & $\begin{array}{c}\text { Thermal conductivity factor } \\
\text { for insulation }\end{array}$ & 1.0 & 0.75 & 0.50 \\
\hline M & $\begin{array}{c}\text { Ratio of in-plane to through- } \\
\text { thickness thermal conductivity } \\
\text { of insulation }\end{array}$ & 1 & 2 & 5 \\
\hline
\end{tabular}

Three structural materials were selected with widely varying thermal properties: a berylliumaluminum alloy (AM162), aluminum, and graphite/epoxy composite. Their thermal properties are listed and compared in Reference 1. The two metals both have high thermal conductivities. However, the 
graphite/epoxy composite has thermal conductivities almost 2 orders of magnitude lower than these two metals. The through-the-thickness conductivity is about a third of the in-plane thermal conductivity for the composite.

A comparison of the heat capacities of the three structural materials is shown in Figure 6. The heat capacities shown in the graph were generated by integrating the specific heat capacities of each material between the initial temperature of $60^{\circ} \mathrm{F}$ and the maximum temperature for that material from Table 5 . These maximum temperatures are not firmly established values, because it is difficult to define precisely the criteria for setting the limit. The limit usually involves a design decision related to the degradation of structural properties with increasing temperature. The limiting temperature for the $\mathrm{Be}-\mathrm{Al}$ alloy was chosen to be $450^{\circ} \mathrm{F}$ because it retains good structural properties at that temperature. This material may be useable at even higher temperatures once its structural properties at elevated temperatures are better known. The limiting temperature selected for aluminum was $350^{\circ} \mathrm{F}$, because that temperature limit was used to design the structure of the Space Shuttle Orbiter. Structural temperature limits ranging between $250^{\circ} \mathrm{F}$ and $300^{\circ} \mathrm{F}$ have been used for graphite/epoxy structures, so the higher value of $300^{\circ} \mathrm{F}$ was chosen for the present study. Figure 6 shows that, even with a $50^{\circ} \mathrm{F}$ difference in temperature limit, the aluminum has only $10 \%$ more heat capacity than the graphite/epoxy. However, the beryllium-aluminum has 2.5 times the heat capacity of aluminum.

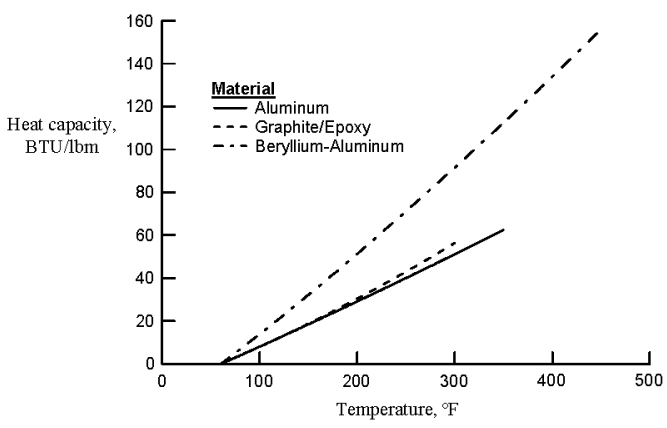

Figure 6: Heat capacities of three structural materials.

The three structural masses chosen for the study are shown in Table 5, along with the corresponding thickness for each of the structural materials. The heaviest mass is comparable to the aluminum skin on the Space Shuttle Orbiter, and the lowest mass is representative of some of the lightweight composite skins on the X-37 flight-test vehicle.

Two other factors were chosen to investigate the effect of adding heat capacity to the system. Beryllium has excellent heat capacity. Therefore, a thin layer of beryllium heat sink was added to the thermal model. One factor defines the mass of the heat sink per unit area, and the other factor defines the location of the beryllium. The beryllium was located either on the outer surface of the structure, the bottom of the insulation (inner surface of the TPS panel) or on the top of the insulation (inner facesheet of the honeycomb sandwich).

Three different factors were used to determine the effect of varying insulation properties: insulation density, a reduction factor on thermal conductivity, and the ratio of in-plane to through-the-thickness thermal conductivity. Three different densities (listed in Table 5) of Saffil ${ }^{\circledR}$ alumina insulation, representative of the range of fibrous insulation densities proposed for use in metallic TPS, were considered. The thermal properties are listed in Reference 1.

Multi-layer insulations have the potential to reduce the effective thermal conductivity to less than half that of Saffil ${ }^{\mathbb{E}}$ alumina at elevated temperatures. ${ }^{4}$ An accurate representation of the thermal response of the multilayer insulation could not readily be incorporated into the finite element thermal model used in this study. A simple reduction factor on the thermal conductivity of the Saffil ${ }^{\mathbb{B}}$ alumina (values of 1.0, 0.75 and 0.50 ) was used to estimate the potential benefits to be gained from improved insulation performance. Multilayer insulations have multiple reflective layers that inhibit radiation through the thickness of the insulation. However, they do not inhibit in-plane radiation, and they provide an in-plane solid conduction path. The inplane conductivities of these multilayer insulations have not yet been measured or predicted. For this study, values of 1,2 , and 5 were used for the ratio of in plane to through-the-thickness thermal conductivity.

Three different factors were used to investigate the effect of metal conduction heat shorts on TPS performance: the combined cross-sectional area of a support bracket and fastener access tube, the crosssectional area of a titanium fastener, and thickness of the foil sides of the TPS panel. The middle level shown in Table 5 for each of these factors corresponds to the approximate value for the ARMOR TPS. The values are doubled for level 3 of all three factors. Level one represents eliminating the bracket, access tube, fastener, and the sides of the TPS panel.

The surface emittance is varied over the range encountered for TPS materials. As previously discussed, the convective heating boundary condition 
allows the surface temperature to vary and adjusts the applied heating accordingly. A more accurate solution would require recalculating convection coefficients and recovery enthalpies for each emittance of interest. However, for this study only the heating histories in Figure 1, calculated for an emittance of 0.86 , were available. Therefore, the effect of surface emittance was modeled using convective boundary condition and heat transfer coefficients and recovery temperatures.

Two additional factors were defined that affected the heat transfer across the gap under the TPS panel: the emittances in the gap and the thickness of the strip of felt under the perimeter of the panel. The emittances of the inner surface of the TPS panel and outer surface of the structure were varied over the widest anticipated range. The thickness of the felt, which is also the width of the gap under the panel, was varied over a plausible range about the value used for the improved metallic TPS concept.

\section{Orthogonal Matrix Analysis}

The next step in the statistical sensitivity analysis was to choose a standard orthogonal array to define the finite element cases to be run. The standard $\mathrm{L}_{27}$ orthogonal array, ${ }^{11}$ shown in Table 6 , fits exactly the 13 factors with three levels each defined in Table 5 . Twenty seven finite element analyses were performed with the combination of factor levels defined in Table 6.

Table $6 \mathrm{~L}_{27}$ standard orthogonal array.

\begin{tabular}{|c|ccccccccccccc|}
\hline $\mathbf{L}_{\mathbf{2}}$ & & \multicolumn{10}{|c|}{ Factors } & $\mathbf{1 0}$ & \\
\hline $\begin{array}{c}\text { Analysis } \\
\text { number }\end{array}$ & $\mathbf{A}$ & $\mathbf{B}$ & $\mathbf{C}$ & $\mathbf{D}$ & $\mathbf{E}$ & $\mathbf{F}$ & $\mathbf{G}$ & $\mathbf{H}$ & $\mathbf{I}$ & $\mathbf{J}$ & $\mathbf{K}$ & $\mathbf{L}$ & $\mathbf{M}$ \\
\hline $\mathbf{1}$ & 1 & 1 & 1 & 1 & 1 & 1 & 1 & 1 & 1 & 1 & 1 & 1 & 1 \\
$\mathbf{2}$ & 1 & 1 & 1 & 1 & 2 & 2 & 2 & 2 & 2 & 2 & 2 & 2 & 2 \\
$\mathbf{3}$ & 1 & 1 & 1 & 1 & 3 & 3 & 3 & 3 & 3 & 3 & 3 & 3 & 3 \\
$\mathbf{4}$ & 1 & 2 & 2 & 2 & 1 & 1 & 1 & 2 & 2 & 2 & 3 & 3 & 3 \\
$\mathbf{5}$ & 1 & 2 & 2 & 2 & 2 & 2 & 2 & 3 & 3 & 3 & 1 & 1 & 1 \\
$\mathbf{6}$ & 1 & 2 & 2 & 2 & 3 & 3 & 3 & 1 & 1 & 1 & 2 & 2 & 2 \\
$\mathbf{7}$ & 1 & 3 & 3 & 3 & 1 & 1 & 1 & 3 & 3 & 3 & 2 & 2 & 2 \\
$\mathbf{8}$ & 1 & 3 & 3 & 3 & 2 & 2 & 2 & 1 & 1 & 1 & 3 & 3 & 3 \\
$\mathbf{9}$ & 1 & 3 & 3 & 3 & 3 & 3 & 3 & 2 & 2 & 2 & 1 & 1 & 1 \\
$\mathbf{1 0}$ & 2 & 1 & 2 & 3 & 1 & 2 & 3 & 1 & 2 & 3 & 1 & 2 & 3 \\
$\mathbf{1 1}$ & 2 & 1 & 2 & 3 & 2 & 3 & 1 & 2 & 3 & 1 & 2 & 3 & 1 \\
$\mathbf{1 2}$ & 2 & 1 & 2 & 3 & 3 & 1 & 2 & 3 & 1 & 2 & 3 & 1 & 2 \\
$\mathbf{1 3}$ & 2 & 2 & 3 & 1 & 1 & 2 & 3 & 2 & 3 & 1 & 3 & 1 & 2 \\
$\mathbf{1 4}$ & 2 & 2 & 3 & 1 & 2 & 3 & 1 & 3 & 1 & 2 & 1 & 2 & 3 \\
$\mathbf{1 5}$ & 2 & 2 & 3 & 1 & 3 & 1 & 2 & 1 & 2 & 3 & 2 & 3 & 1 \\
$\mathbf{1 6}$ & 2 & 3 & 1 & 2 & 1 & 2 & 3 & 3 & 1 & 2 & 2 & 3 & 1 \\
$\mathbf{1 7}$ & 2 & 3 & 1 & 2 & 2 & 3 & 1 & 1 & 2 & 3 & 3 & 1 & 2 \\
$\mathbf{1 8}$ & 2 & 3 & 1 & 2 & 3 & 1 & 2 & 2 & 3 & 1 & 1 & 2 & 3 \\
$\mathbf{1 9}$ & 3 & 1 & 3 & 2 & 1 & 3 & 2 & 1 & 3 & 2 & 1 & 3 & 2 \\
$\mathbf{2 0}$ & 3 & 1 & 3 & 2 & 2 & 1 & 3 & 2 & 1 & 3 & 2 & 1 & 3 \\
$\mathbf{2 1}$ & 3 & 1 & 3 & 2 & 3 & 2 & 1 & 3 & 2 & 1 & 3 & 2 & 1 \\
$\mathbf{2 2}$ & 3 & 2 & 1 & 3 & 1 & 3 & 2 & 2 & 1 & 3 & 3 & 2 & 1 \\
$\mathbf{2 3}$ & 3 & 2 & 1 & 3 & 2 & 1 & 3 & 3 & 2 & 1 & 1 & 3 & 2 \\
$\mathbf{2 4}$ & 3 & 2 & 1 & 3 & 3 & 2 & 1 & 1 & 3 & 2 & 2 & 1 & 3 \\
$\mathbf{2 5}$ & 3 & 3 & 2 & 1 & 1 & 3 & 2 & 3 & 2 & 1 & 2 & 1 & 3 \\
$\mathbf{2 6}$ & 3 & 3 & 2 & 1 & 2 & 1 & 3 & 1 & 3 & 2 & 3 & 2 & 1 \\
$\mathbf{2 7}$ & 3 & 3 & 2 & 1 & 3 & 2 & 1 & 2 & 1 & 3 & 1 & 3 & 2 \\
\hline
\end{tabular}

The TPS sizing finite element model described previously was used to perform the analyses defined in Table 6. The model was modified by adding a line of one-dimensional conduction elements to represent a thin layer of beryllium at the location specified by factor $\mathrm{K}$ in Table 5 and the mass defined by factor $\mathrm{A}$ of Table 5. An initial temperature of $60^{\circ} \mathrm{F}$ was used, and no heat loss was assumed on the inner surface of the structure. An ambient temperature of $60^{\circ} \mathrm{F}$ with a 10 mph wind was assumed after landing. And, as previously stated, a convective heating boundary condition was used with heat transfer coefficients and recovery temperatures derived in Reference 1.

Table 7 Results of parametric TPS sizing for several design issues.

\begin{tabular}{|c|c|c|c|c|c|c|c|c|}
\hline \multirow{2}{*}{$\begin{array}{l}\text { Analysis } \\
\text { number }\end{array}$} & \multirow{2}{*}{$\begin{array}{c}\text { TPS } \\
\text { thick., } \\
\text { in. }\end{array}$} & \multirow{2}{*}{$\begin{array}{c}\text { TPS } \\
\text { mass } \\
\text { per unit } \\
\text { area, } \\
\mathbf{l b}_{\mathbf{m}} / \mathrm{ft}^{2}\end{array}$} & \multicolumn{3}{|c|}{$\begin{array}{c}\text { Maximum structural } \\
\text { temperature }\end{array}$} & \multicolumn{2}{|c|}{$\begin{array}{c}\text { Maximum } \\
\text { structural } \\
\text { temp. at } \\
\text { panel center }\end{array}$} & \multirow{2}{*}{$\begin{array}{c}\text { Max. } \\
\text { surface } \\
\text { temp., } \\
{ }^{0} \mathrm{~F}\end{array}$} \\
\hline & & & ${ }^{\circ} \mathbf{F}$ & $\underset{\mathbf{s}}{\text { Time, }}$ & & ${ }^{\circ} \mathrm{F}$ & $\underset{s}{\text { Time, }}$ & \\
\hline 1 & 322 & 1.067 & 49.6 & 2210 & e & 448.3 & 2240 & 1437.7 \\
\hline 2 & 21 & 1.103 & 449.9 & 2180 & edg & 447.7 & 2250 & 1439.8 \\
\hline 3 & 1.010 & 1.144 & 449.8 & 2160 & edge & 447.3 & 2260 & 1442.1 \\
\hline 4 & 57 & 1.327 & 350.0 & 3160 & center & 350.0 & 3160 & 1553.6 \\
\hline 5 & 4.006 & 1.917 & 350.0 & 3700 & center & 350.0 & 3700 & 1550.6 \\
\hline 6 & 2.248 & 1.879 & 350.1 & 3390 & center & 350.1 & 3390 & 1550.6 \\
\hline 7 & 8.123 & 2.118 & 299.8 & 6190 & edge & 294.4 & 7500 & 1697.6 \\
\hline 8 & 4.012 & 1.860 & 299.8 & 4530 & edge & 288.2 & 6770 & 1698.4 \\
\hline 9 & 4.011 & 2.828 & 300.2 & 4420 & edge & 286.3 & 7180 & 1693.5 \\
\hline 10 & 4.793 & 1.614 & 349.9 & 3460 & center & 349.9 & 3460 & 1446.7 \\
\hline 11 & 2.892 & 1.660 & 349.8 & 3450 & center & 349.8 & 3450 & 1447.1 \\
\hline 12 & 2.874 & 2.330 & 350.2 & 3770 & center & 350.2 & 3770 & 1334.5 \\
\hline 13 & 396 & 1.737 & 300.0 & 3310 & edge & 280.3 & 5000 & 1420.9 \\
\hline 14 & 3.010 & 1.794 & 299.9 & 2770 & edge & 291.7 & 4000 & 1551.9 \\
\hline 15 & 10 & 1.539 & 300.0 & 2600 & edge & 289.8 & 3440 & 1551.9 \\
\hline 16 & 84 & 1.291 & 449.8 & 2460 & center & 449.8 & 2460 & 1694.6 \\
\hline 17 & 60 & 1.522 & 450.1 & 2520 & edge & 449.8 & 2600 & 1524.9 \\
\hline 18 & 00 & 1.424 & 449.8 & 2400 & between & 449.4 & 2470 & 1693.3 \\
\hline 19 & 28 & 1.485 & 299.9 & 26 & edge & 296.2 & 3230 & 1447.2 \\
\hline 20 & 24 & 1.818 & 299.8 & 30 & edge & 297.7 & 3480 & 1445.0 \\
\hline 21 & 01 & 2.281 & 300.1 & 27 & edge & 258.0 & 6050 & 1323.9 \\
\hline 22 & 3.521 & 1.596 & 449.9 & 2630 & edge & 449.6 & 2740 & 1404.4 \\
\hline 23 & 1.646 & 1.434 & 449.8 & 2460 & center & 449.8 & 2460 & 1551.7 \\
\hline 24 & 1.807 & 1.733 & 450.1 & 2660 & center & 450.1 & 2660 & 1548.7 \\
\hline 25 & 5.033 & 1.931 & 350.0 & 3600 & center & 350.0 & 3600 & 1695.2 \\
\hline 26 & 2.880 & 1.691 & 350.0 & 3370 & center & 350.0 & 3370 & 1507.6 \\
\hline 27 & 1.564 & 1.712 & 349.8 & 2830 & center & 349.8 & 2830 & 1697.0 \\
\hline Mean & 3.027 & 1.698 & 366.6 & 3137 & & 362.0 & 3686 & 1531.5 \\
\hline
\end{tabular}

The results of the 27 TPS sizing analyses are shown in Table 7. For each finite element TPS sizing analysis defined by Table 6 a number of results are shown. The TPS thickness was calculated by adding the insulation thickness from the sizing analysis to the thickness of the outer Inconel honeycomb sandwich and the thickness of the strip of felt under the perimeter of the panel. The TPS mass per unit area was calculated from the insulation thickness from the sizing analysis and the mass properties of ARMOR TPS. The maximum structural temperature, the time when it occurred and 
the location where it occurred are listed. In all but one case, the maximum structural temperature occurred either under the center of the TPS panel or at the edge of the model under the panel-to-panel gap. In one case the maximum structural temperature occurred between these locations, nearer to the panel edge. The maximum structural temperature and the time when it occurred are also shown for the structure under the center of the panel. Finally, the maximum surface temperature at the center of the TPS panel is shown for each TPS sizing analysis.

A wide range of TPS thicknesses and masses are predicted. TPS concepts may need to be modified somewhat for some of the more extreme variations to carry required loads. The most obvious change would be varying the cross-sectional area of the support bracket with changes in insulation thickness. Because the bracket cross-sectional area is already one of the factors being varied, this design change is already included. For analysis number 3, the height of the lower titanium frame had to be reduced from $0.5 \mathrm{in}$. to 0.3 in. to complete the sizing analysis. The insulation was sized to be 0.46 in. thick. These minor modifications to the TPS design should have a minimal effect on the results.

The maximum structural temperatures give an indication of the convergence tolerance used in the sizing analysis. The maximum structural temperature corresponds closely to the specified limit temperature for the structural material used in each analysis, so it is obvious which structural material was used (graphite/epoxy $-300^{\circ} \mathrm{F}$, aluminum $-350^{\circ} \mathrm{F}$, berylliumaluminum $-450^{\circ} \mathrm{F}$ ). For all 27 analyses the maximum temperature was within $0.4^{\circ} \mathrm{F}$ of the specified structural limit temperature. In a number of cases, the maximum temperature occurred before landing at 2600 seconds. For every case where the maximum structural temperature occurred before landing, the structural material was beryllium-aluminum. The other two structural materials always reached their maximum temperature after landing.

The location of the maximum structural temperature provides information about the interaction between the TPS and the underlying structure. The aluminum structure always reaches its maximum temperature under the center of the panel, indicating that the heat shorts at the perimeter of the panel do not size the TPS panel. For the composite substructure, the maximum structural temperature always occurs at the edge of the panel indicating that the heat shorts at the perimeter of the panel size the TPS panel. There is a significant difference between the maximum structural temperature and the maximum structural temperature at the center of the panel and between the times at which they occurred for several analyses with the composite structure. This indicates that the low thermal conductivity of the composite material did not allow all of the heat capacity of the material to be used, because much of the structure did not reach its maximum temperature. The variable thickness two-dimensional thermal model used in this analysis distributes all heat shorts uniformly around the perimeter of the panel, so the heat short problem may be more severe than predicted. The local heat shorts at the TPS panel corners, due to the fastener, support bracket and fastener access tube, may cause a more severe, localized hot spot in a structural material with thermal conductivities as low as the composite material used in the current study. A three-dimensional model is required to predict the effects of the localized heat shorts in the composite substructure adequately. If the local hot spots are severe, the TPS concept may need to be modified to reduce the localized heat shorts or a structural material with higher thermal conductivity may be used.

For the analyses in Table 7 with a berylliumaluminum structure, some of the maximum structural temperatures occur under the center of the TPS panel, some at the edge, and one in between. However, for cases where the maximum structural temperature occurs away from the center, the maximum temperature at the panel center is very close to the maximum structural temperature and the times at which they occur are not far apart. Heat shorts, therefore do not play a significant role in sizing TPS for a beryllium-aluminum structure. The variable thickness two-dimensional thermal model is adequate for analyzing metallic TPS on either of the two high-thermal-conductivity metal structures.

Table 8 summarizes the results of an ANOM and an ANOVA for the TPS thicknesses. The four most important factors involve the structure and the insulation. Insulation density is the most important factor, and the table shows that using lower density insulations results in thicker TPS, as expected. Using the lower density $1.5 \mathrm{lb}_{\mathrm{m}} / \mathrm{ft}^{3}$ insulation (Level 1 ) rather than the $3.0 \mathrm{lb} / \mathrm{ft}^{3}$ insulation (Level 2), which has been used in previous metallic TPS concepts, results in a thickness increase of 1.40 in. (46\% of the mean thickness). Using the denser $6.0 \quad 1 b_{m} / \mathrm{ft}^{3}$ insulation (Level 3) results in a thickness decrease of $0.68 \mathrm{in}$. ( $22 \%$ of the mean thickness) compared to the $3.0 \mathrm{lb}_{\mathrm{m}} / \mathrm{ft}^{3}$ insulation (Level 2). The insulation conductivity factor is also important, showing the biggest change between a factor of 0.75 (Level 2) and a factor of 0.5 (Level 3) times the conductivity of the fibrous insulation. 
Table 8 Results of an ANOM and an ANOVA of TPS thicknesses calculated for TPS design factors.

\begin{tabular}{|c|c|c|c|c|c|c|c|c|c|}
\hline \multirow{2}{*}{\multicolumn{2}{|c|}{\begin{tabular}{|c|} 
TPS Thickness \\
Factor \\
\end{tabular}}} & \multicolumn{3}{|c|}{$\begin{array}{l}\text { Differences from mean, } \\
\text { in. (factor effects) }\end{array}$} & \multirow[t]{2}{*}{ SS } & \multirow{2}{*}{\begin{tabular}{|c|}
$\%$ \\
Total \\
SS \\
\end{tabular}} & \multirow[t]{2}{*}{ dof } & \multirow{2}{*}{$\begin{array}{c}\text { Mean } \\
\text { SS }\end{array}$} & \multirow[t]{2}{*}{$\mathbf{F}$} \\
\hline & & Level 1 & Level 2 & Level 3 & & & & & \\
\hline $\mathbf{E}$ & $\begin{array}{c}\text { Insulation } \\
\text { density }\end{array}$ & 1.146 & -0.233 & -0.913 & 19.81 & 31.23 & 2 & 9.905 & 28.41 \\
\hline $\mathbf{C}$ & $\begin{array}{l}\text { Structural } \\
\text { material }\end{array}$ & -1.141 & 0.289 & 0.852 & 19.02 & 29.97 & 2 & 9.508 & 27.27 \\
\hline D & $\begin{array}{l}\text { Structural } \\
\text { mass }\end{array}$ & -0.422 & -0.293 & 0.715 & 6.98 & 11.00 & 2 & 3.489 & 10.01 \\
\hline $\mathbf{L}$ & $\begin{array}{c}\text { Insulation } \mathrm{k} \\
\text { factor }\end{array}$ & 0.354 & 0.284 & -0.638 & 5.52 & 8.70 & 2 & 2.759 & 7.91 \\
\hline B & $\begin{array}{c}\text { Surface } \\
\text { emittance } \\
\end{array}$ & -0.215 & -0.060 & 0.480 & 2.53 & 3.98 & 2 & 1.264 & 3.62 \\
\hline I & $\begin{array}{c}\text { Felt } \\
\text { thickness }\end{array}$ & -0.321 & -0.057 & 0.378 & 2.24 & 3.53 & 2 & 1.119 & 3.21 \\
\hline $\mathbf{H}$ & $\begin{array}{c}\text { Side } \\
\text { thickness }\end{array}$ & -0.298 & -0.062 & 0.360 & 2.00 & 3.16 & 2 & 1.002 & 2.87 \\
\hline$* \mathbf{J}$ & \begin{tabular}{|l|} 
Under panel \\
gap \\
emittances \\
\end{tabular} & -0.022 & -0.286 & 0.307 & 1.59 & 2.50 & 2 & 0.794 & \\
\hline${ }^{*} \mathrm{~A}$ & $\begin{array}{c}\text { Be heat sink } \\
\text { mass }\end{array}$ & 0.307 & -0.092 & -0.215 & 1.34 & 2.12 & 2 & 0.672 & \\
\hline${ }^{*} \mathbf{M}$ & \begin{tabular}{|c|} 
In-plane \\
insulation $k$ \\
ratio
\end{tabular} & -0.202 & 0.146 & 0.056 & 0.59 & 0.93 & 2 & 0.294 & \\
\hline$* \mathbf{K}$ & \begin{tabular}{|c|}
$\begin{array}{c}\text { Be heat sink } \\
\text { location }\end{array}$ \\
\end{tabular} & -0.207 & 0.100 & 0.108 & 0.58 & 0.91 & 2 & 0.290 & \\
\hline$* \mathrm{G}$ & Fastener area & 0.055 & -0.060 & 0.005 & 0.06 & 0.09 & 2 & 0.030 & \\
\hline${ }^{*} \mathbf{F}$ & $\begin{array}{c}\text { Bracket/tube } \\
\text { area }\end{array}$ & -0.034 & 0.038 & -0.003 & 0.02 & 0.04 & 2 & 0.012 & \\
\hline \multirow{2}{*}{\multicolumn{2}{|c|}{ Pooled Error $(*)$}} & & & & $(4.18)$ & & (12) & $(0.349)$ & \\
\hline & & & & Total & 4.007 & 100.0 & & & \\
\hline
\end{tabular}

The structural material has nearly as large an effect on the TPS thickness as the insulation density. The extra heat capacity of the beryllium-aluminum accounts for most of the variation. The difference between the TPS thickness required for the aluminum structure (Level 2) and for the beryllium-aluminum structure

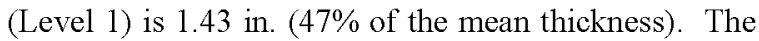
difference between the results for aluminum (Level 2) and graphite/epoxy (Level 3) of 0.56 in. (19\% of mean thickness) is partly due to the $10 \%$ difference in heat capacities and partly due to the heat shorts discussed earlier

The mass of the structure to be protected by the TPS also has a significant effect on required TPS thickness because it defines the amount of material available to store the heat passing through the TPS. The TPS thickness required for $0.75 \mathrm{lb}_{\mathrm{m}} / \mathrm{ft}^{2}$ of structure (Level 3) is 1.01 in. (33\% of mean thickness) greater than that required for $1.25 \mathrm{lb} / \mathrm{ft}^{2}$ of structure (Level 2). The lighter structures require a greater TPS thickness.

Surface emittance has a significantly smaller effect on TPS thickness than the four factors discussed previously. However, the results show that there is a much bigger change in going from a surface emittance of 0.8 (Level 2) to 0.6 (Level 3) than in going from 1.0 (Level 1) to 0.8 (Level 2). This trend is consistent with the trend observed for the maximum surface temperatures.

One of the reasons the felt thickness affects the total thickness of the TPS is that the panel sits on top of the felt strip, so the felt thickness is added to the TPS panel thickness to get the total TPS thickness. The observed variations are greater than the variations in felt thickness, so there are also some associated variations in heat transfer through the TPS

The thickness of the TPS panel sides has the greatest effect of any of the factors related to heat shorts because it represents the largest variation in crosssectional area for metal conduction. The other heat shorts have a negligible effect. The remaining factors have small effects on the TPS thickness.

Table 9 Results of an ANOM and an ANOVA of TPS masses calculated for TPS design factors.

\begin{tabular}{|c|c|c|c|c|c|c|c|c|c|}
\hline \multirow{2}{*}{\multicolumn{2}{|c|}{$\begin{array}{c}\text { TPS Mass } \\
\text { Factor } \\
\end{array}$}} & \multirow{2}{*}{\multicolumn{3}{|c|}{ 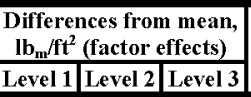 }} & \multirow{3}{*}{$\begin{array}{c}\text { SS } \\
1.573\end{array}$} & \multirow{3}{*}{ 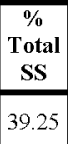 } & \multirow{3}{*}{$\frac{\text { dof }}{2}$} & \multirow{3}{*}{\begin{tabular}{|c|}
$\begin{array}{c}\text { Mean } \\
\text { SS }\end{array}$ \\
0.786 \\
\end{tabular}} & \multirow{3}{*}{$\begin{array}{c}\mathbf{F} \\
59.33\end{array}$} \\
\hline & & & & & & & & & \\
\hline C & $\begin{array}{c}\text { Structural } \\
\text { material }\end{array}$ & -0.329 & 0.087 & 0.242 & & & & & \\
\hline D & $\begin{array}{c}\text { Structural } \\
\text { mass }\end{array}$ & -0.173 & -0.037 & 0.211 & 0.682 & 17.02 & 2 & 0.341 & 25.73 \\
\hline $\mathrm{L}$ & \begin{tabular}{|c|} 
Insulation \\
$\mathrm{k}$ factor
\end{tabular} & 0.178 & 0.025 & -0.203 & 0.662 & 16.52 & 2 & 0.331 & 24.98 \\
\hline $\mathrm{E}$ & \begin{tabular}{|c|}
$\begin{array}{c}\text { Insulation } \\
\text { density }\end{array}$ \\
\end{tabular} & -0.124 & -0.053 & 0.177 & 0.444 & 11.08 & 2 & 0.222 & 16.75 \\
\hline B & \begin{tabular}{|c|} 
Surface \\
emittance
\end{tabular} & -0.086 & -0.036 & 0.122 & 0.213 & 5.31 & 2 & 0.106 & 8.03 \\
\hline $\mathrm{H}$ & \begin{tabular}{|c|}
$\begin{array}{c}\text { Side } \\
\text { thickness }\end{array}$ \\
\end{tabular} & -0.099 & -0.008 & 0.107 & 0.191 & 4.76 & 2 & 0.095 & 7.20 \\
\hline $\mathbf{M}$ & \begin{tabular}{|c} 
In-plane \\
insulation \\
$\mathrm{k}$ ratio
\end{tabular} & 0.066 & 0.005 & -0.070 & 0.084 & 2.08 & 2 & 0.042 & 3.15 \\
\hline${ }^{*} \mathbf{F}$ & \begin{tabular}{|c|} 
Bracket/tu \\
be area
\end{tabular} & -0.059 & -0.003 & 0.062 & 0.066 & 1.65 & 2 & 0.033 & \\
\hline${ }^{*} \mathrm{~A}$ & \begin{tabular}{|c|}
$\begin{array}{c}\text { Be heat } \\
\text { sink mass }\end{array}$ \\
\end{tabular} & -0.004 & -0.041 & 0.045 & 0.033 & 0.83 & 2 & 0.017 & \\
\hline$* \mathrm{I}$ & \begin{tabular}{|c|c}
$\begin{array}{c}\text { Felt } \\
\text { thickness }\end{array}$ \\
\end{tabular} & 0.008 & 0.033 & -0.041 & 0.026 & 0.64 & 2 & 0.013 & \\
\hline${ }^{*} \mathbf{J}$ & \begin{tabular}{|c|c|} 
Under \\
panel gap \\
emittances \\
\end{tabular} & -0.001 & 0.034 & -0.033 & 0.020 & 0.50 & 2 & 0.010 & \\
\hline${ }^{*} \mathbf{K}$ & $\begin{array}{l}\text { Be heat } \\
\text { sink } \\
\text { location }\end{array}$ & 0.000 & -0.023 & 0.023 & 0.010 & 0.24 & 2 & 0.005 & \\
\hline${ }^{*} \mathrm{G}$ & $\begin{array}{l}\text { Fastener } \\
\text { area }\end{array}$ & -0.007 & -0.010 & 0.017 & 0.004 & 0.10 & 2 & 0.002 & \\
\hline & $\begin{array}{l}\text { oled Error } \\
(*)\end{array}$ & & & & $(0.159)$ & & (12) & $(0.013)$ & \\
\hline & & & & Total & 4.007 & 100.0 & & & \\
\hline
\end{tabular}

Table 9 presents the results of an ANOM and an ANOVA for the TPS masses. Factors related to the structure and insulation dominate the variations in TPS mass. The structural material has the largest effect on TPS mass variations. The beryllium-aluminum structure (Level 1) requires $0.42 \mathrm{lb}_{\mathrm{m}} / \mathrm{ft}^{2}$ ( $25 \%$ of mean mass) less TPS than the aluminum structure (Level 2) and $0.71 \mathrm{lb}_{\mathrm{m}} / \mathrm{ft}^{2}$ ( $34 \%$ of mean mass) less TPS than the graphite/epoxy structure (Level 3). The much higher 
heat capacity of the beryllium-aluminum (see Figure 6) accounts for most of the reduced TPS mass. However, the low thermal conductivity of the graphite/epoxy resulted in the TPS being sized for heat shorts and accounts for much of the difference between the results for aluminum and graphite/epoxy.

The structural mass also has a significant effect on the mass of TPS required. Thinner, lighter structural skins are good, but they require more TPS mass to protect them from aerodynamic heating. This principle can be illustrated with the values in Table 9. Reducing the structural mass from $1.75 \mathrm{lb}_{\mathrm{m}} / \mathrm{ft}^{2}$ (Level 1) to 1.25 $\mathrm{lb}_{\mathrm{m}} / \mathrm{ft}^{2}$ (Level 2) means that an additional $0.136 \mathrm{lb}_{\mathrm{m}} / \mathrm{ft}^{2}$ of TPS is required. So $27 \%$ of the $0.5 \mathrm{lb} / / \mathrm{ft}^{2}$ savings in structural mass will be lost to increased TPS. Further reducing the structural mass from $1.25 \mathrm{lb}_{\mathrm{m}} / \mathrm{ft}^{2}$ (Level 2) to $0.75 \mathrm{lb}_{\mathrm{m}} / \mathrm{ft}^{2}$ (Level 3 ) means that an additional 0.248 $1 b_{\mathrm{m}} / \mathrm{ft}^{2}$ of TPS is required. This means that $50 \%$ of the $0.5 \mathrm{lb}_{\mathrm{m}} / \mathrm{ft}^{2}$ savings in structural mass will be lost to increased TPS. Clearly the TPS and structure should be designed concurrently.

The insulation properties also have a significant effect on the required TPS mass. The most important insulation property is the insulation conductivity. Cutting the insulation conductivity in half (difference between Levels 1 and 3 ) reduces the TPS mass by 0.38 $\mathrm{lb}_{\mathrm{m}} / \mathrm{ft}^{2}$ (22\% of mean mass). Such a reduction can be achieved readily with multilayer insulations. Lower density insulations reduce TPS mass; however, they also increase TPS thickness. This factor most directly illustrates the trade-off between TPS thickness and mass. The penalty associated with TPS thickness must come from a study of the effect of TPS thickness on vehicle packaging efficiency and overall performance. A minimum mass TPS may not provide the best overall vehicle performance. Thinner, slightly heavier TPS may be optimum.

Surface emittance has a much smaller effect on TPS mass than factors related to the structure and insulation just discussed. There is little change in required TPS mass for a change in emittance from 1.0 (Level 1) to 0.8 (Level 2). However, a change in surface emittance from 0.8 (Level 2) to 0.6 (Level 3) produces an increase in TPS mass of $0.23 \mathrm{lb}_{\mathrm{m}} / \mathrm{ft}^{2}$ (14\% of mean mass). Because of increased TPS mass and thickness and because of increased maximum surface temperatures, emittances below 0.8 should be avoided.

Two factors associated with heat shorts have a small effect on TPS mass. The thickness of the foil sides has a larger effect on the TPS mass than the bracket and tube area. Not only do the sides provide a larger metal conduction path, the thicker sides weigh more than the brackets and tubes.
The in-plane thermal conductivity of the insulation has a small effect on the TPS mass, but it is unclear why increased lateral thermal conductivity would decrease the mass of TPS required. The remaining factors contribute very little to the variation in required TPS mass.

\section{Conclusions}

A number of clear conclusions with far-reaching implications became apparent from the results of these studies. The most important of these are:

- TPS sizing is very sensitive to structural heat loss. There is potential to save significant TPS mass if the actual heat loss can be modeled.

- TPS sizing is sensitive to the initial temperature of a vehicle structure and TPS prior to atmospheric reentry. For calculating the required mass and thickness of TPS, the initial temperature should be determined with care.

- Gaps between TPS panels are significant heat shorts. If gaps exist, the heat transfer must be modeled accurately to get the correct TPS performance. They should be eliminated by design if possible.

- The TPS and structure need to be designed concurrently for mass efficiency.

- The thermal properties of the structure can have a great effect on the TPS required.

- The heat capacity of the structural material, which includes both the specific heat and temperature limit, should be as high as possible. A beryllium-aluminum alloy required significantly less TPS than the other two structural materials studied.

- A structural material with low thermal conductivity, such as the graphite/epoxy composite in this study, can be very sensitive to local heat shorts. A three- dimensional thermal model may be required to address the issue adequately.

- The heat shorts in the improved metallic TPS panel had little effect on TPS performance for the high-thermal-conductivity metal structures studied.

- TPS mass may be reduced significantly by reducing the thermal conductivity of insulations.

\section{$\underline{\text { References }}$}

\footnotetext{
${ }^{1}$ Blosser, M. L., "Advanced Metallic Thermal Protection Systems for Reusable Launch Vehicles", Ph. D. Dissertation, UVA, May 2000.
} 
${ }^{2}$ Dorsey, John T.; Poteet, Carl; and Chen, Roger: "Metallic Thermal Protection System Technology Development: Concepts, Requirements and Assessment Overview," $40^{\text {th }}$ AIAA Aerospace Sciences Meeting and Exhibit, Reno, NV, January 1417, 2002.

${ }^{3}$ Poteet, Carl; Abu-Khajeel, Hasan,; and Hsu, Su-Yuen: "Preliminary Thermal-Mechanical Sizing of Metallic TPS: Process Development and Sensitivity Studies," $40^{\text {th }}$ AIAA Aerospace Sciences Meeting and Exhibit, Reno, NV, January 14-17, 2002.

${ }^{4}$ Daryabeigi, K.: "Design of High Temperature Multi-layer Insulation for Reusable Launch Vehicles," PhD Dissertation, University of Virginia, May 2000.

${ }^{5}$ Blosser, M.L.; Chen, R.R.; Schmidt, I.H.; Dorsey, J.T.; Poteet, C.C.; and Bird, R.K.: "Advanced Metallic Thermal Protection System Development," $40^{\text {th }}$ AIAA Aerospace Sciences Meeting and Exhibit, Reno, NV, January 14-17, 2002.

${ }^{6}$ Sawyer, J. W., Hodge, J., \& Moore, B., 1998, Aero/Thermal Test of Metallic TPS for X-33 Reusable Launch Vehicle, 3rd European Workshop on Thermal Protection Systems, ESTEC, The Netherlands.

7 Whetstone, W.D.: "EISI-EAL Engineering Analysis Language Reference Manual, System Level 335," Engineering Information Services, Inc., San Jose, CA, Oct. 1998

${ }^{8}$ Marlowe, M.B.; Moore, R.A.; and Whetstone, W.D.: "SPAR Thermal Analysis Processors Reference Manual, System Level 16," NASA CR-159162, 1979.

${ }^{9}$ Kreith, F.; and Black, W.Z.: Basic Heat Transfer, Harper \& Row, Publishers, New York, 1980.

${ }^{10}$ Gorton, M.P.; Shideler, J.L.; and Webb, G.L.: "Static and Aerothermal Tests of a Superalloy Honeycomb Prepackaged Thermal Protection System," NASA TP 3257, March, 1993.

${ }^{11}$ Phadke, M.S.: Quality Engineering using Robust Design, Prentice Hall, Englewood Cliffs, NJ, 1989.

${ }^{12}$ Ross, P.J.: Taguchi Techniques for Quality Engineering: Loss Function, Orthogonal Experiments, Parameter and Tolerance Design, Second edition, McGrawHill, New York, 1996.

${ }^{13}$ Norris, P.M.: "Application of Experimental Design Methods to Assess the Effect of Uncertain Boundary Conditions in Inverse Heat Transfer Problems," International Journal of Heat and Mass Transfer, Vol. 41, No. 2, pp.313-322, 1998.

${ }^{14}$ Kakac, S.; Shah, R.K.; and Aung, W.: Handbook of SinglePhase Convective Heat Transfer, John Wiley \& Sons, New York, 1987.
${ }^{15}$ Ko, W.L.; Quinn, R.D.; and Gong, L.: "Finite-Element Reentry Heat Transfer Analysis of Space Shuttle Orbiter," NASA TP 2657, Dec., 1986. 